\title{
Kematian Perinatal di Indonesia dan Faktor yang Berhubungan, Tahun 1997-2003
}

\author{
Meidy Farenti Prameswari*
}

\begin{abstract}
Abstrak
WHO memperkirakan bahwa setiap tahun lebih dari 9 juta bayi meninggal pada periode perinatal dan hampir semua terjadi di negara berkembang. Kini angka kematian perinatal di Indonesia adalah 24 per 1000 kelahiran, sekitar 77\% merupakan sumbangan kematian neonatal. Tujuan penelitian ini adalah mengetahui faktor-faktor yang berhubungan dengan kejadian kematian perinatal di Indonesia dan memperkirakan program intervensi yang paling berperan dan menurunkannya. Studi ini menggunakan sdumber data sekunder Survei Demografi Kesehatan Indonesia (SDKI) tahun 2002-2003. Desain penelitian yang digunakan adalah potong lintang (cross sectional). Hasil menemukan variabel yang berhubunganterhadap kematian perinatal di Indonesia selama periode 1997-2003 adalah jarak kelahiran;komplikasi persalinan; tingkat pendidikan ibu; BBLR; tenaga penolong persalinan; riwayat kunjungan ANC; riwayat, serta wilayah tempat tinggal ibu. Berdasarkan perhitungan PAR, BBLR memiliki nilai PAR\% sebesar 14,90. Artinya jika penurunan angka kematian perinatal difokuskan kepada program intervensi untuk menurunkan prevalensi bayi BBLR maka akan terjadi pengurangan resiko kematian perinatal sebesar $15 \%$ dari total kasus di seluruh populasi bayi lahir hidup.
\end{abstract}

Kata kunci : Kematian perinatal, BBLR, ANC

\begin{abstract}
WHO predicted that every year there are more than 9 millions perinatal deaths and almost all occurred in developing countries. In Indonesia, at present time the perinatal mortality rate is 24 per 1000 life birth, and about $77 \%$ was contributed by neonatal death. The objective of this study is to know factors related to perinatal mortality in Indonesia and to assess the most important intervention program to reduce it. The study used secondary data source, that is Indonesian Demographic and Health Survey (IDHS) in the period of 2002-2003. Design of the study is cross sectional. The results show that variables related to perinatal mortality are parity, delivery complications, maternal education, low birth weight, birth assistant, ANC visit, and residential address. Based on PAR calculation, low birth weight has PAR\% of 14.90 meaning that if intervention program is focused on reducing prevalence of low birth weight, the perinatal mortality risk will be reduced by around $15 \%$ of the total cases among live newborn infants population.
\end{abstract}

Key words : Perinatal mortality, low birth weight, ANC 
Setiap tahun, di seluruh dunia, diperkirakan terjadi 4,3 juta kelahiran mati dan 3,3 juta kematian neonatal. Angka tersebut dihitung dalam kondisi sekitar 40\% kasus yang tidak dilaporkan. ${ }^{1}$ Meskipun sampai kini, angka kematian bayi di berbagai negara telah mengalami penurunan, kontribusi kematian neonatal pada kematian bayi semakin tinggi. Kondisi tersebut dialami oleh hampir setiap negara di dunia. ${ }^{2}$ Langkah maju mengendalikan masalah kematian bayi telah memperlihatkan hasil yang menggembirakan. Namun, WHO memperkirakan lebih dari 9 juta bayi meninggal sebelum lahir atau pada minggu pertama kehidupannya (periode perinatal), setiap tahun. Hampir semua kematian tersebut terjadi di negara berkembang. ${ }^{3}$ Angka kematian perinatal (Perinatal Mortality Rate) (PMR) di negara berkembang (50/1000) adalah lima kali lebih tinggi daripada negara maju (10/1000). ${ }^{4}$

Pengendalian kematian perinatal akan berkontribusi sangat besar terhadap penurunan angka kematian bayi. Penurunan kematian perinatal di negara berkembang termasuk Indonesia, akan sangat ditentukan oleh penatalaksanaan kesehatan ibu pada saat kehamilan, menjelang persalinan, saat persalinan dan setelah persalinan. Beberapa penelitian telah membuktikan bahwa kelangsungan hidup pada masa perinatal juga dipengaruhi oleh sejumlah faktor meliputi karakteristik demografi dan sosial ibu, riwayat kesehatan reproduksi ibu, kondisi kesehatan bayi dan kondisi lingkungan tempat tinggal. ${ }^{1}$

Berdasarkan laporan SDKI 2002-2003, saat ini tingkat kematian perinatal di Indonesia adalah 24 per 1000 kelahiran menyumbang sekitar 77\% dari kematian neonatal, dimana kematian neonatal menyumbang $58 \%$ dari total kematian bayi. ${ }^{5}$ Laporan SDKI 2002-2003 telah menyajikan angka kematian perinatal di Indonesia. Namun, laporan tersebut belum menyajikan berbagai faktor apa saja yang berhubungan dengan kematian perinatal di Indonesia. Padahal pengetahuan tentang faktor-faktor yang berhubungan dengan kematian perinatal selama kurun waktu tersebut, berguna untuk menilai dan mengembangkan berbagai program intervensi yang efisien dan efektif dalam menurunkan angka kematian perinatal.

\section{Metode}

Disain epidemiologi yang digunakan dalam penelitian ini adalah disain studi kros seksional. Sumber data adalah data sekunder yang diperoleh dari data set SDKI 2002-2003 yang sudah dipublikasikan oleh Badan Pusat Statistik pada tahun 2003. Instrumen pengumpulan data yang digunakan dalam SDKI 2002-2003 adalah kuesioner yang terdiri dari 3 macam kuesioner, yaitu kuesioner Daftar Rumah Tangga, Daftar Pertanyaan Wanita, dan Daftar Pertanyaan Pria. Penelitian ini menggunakan data yang berasal dari dua daftar pertanyaan pertama.

Populasi adalah semua bayi lahir hidup dan lahir mati yang dilahirkan oleh wanita usia subur di Indonesia. Sampel adalah semua bayi anak terakhir responden wanita SDKI 2002-2003 yang lahir hidup dan lahir mati, pada kurun waktu 1997- 2003. Ukuran sampel minimal yang dihitung berdasarkan rumus dua proporsi dari Lemeshow, dengan mengacu angka prevalensi kematian perinatal pada tiap pajanan didapatkan hasil sampel minimum adalah sebesar 1.372 responden. Peneliti memutuskan untuk mengambil seluruh populasi menjadi sampel penelitian yang berjumlah 6.758 responden. Berdasarkan hasil perhitungan sampel minimal dan perhitungan sampel yang ada pada data set, maka jumlah sampel minimal yang dibutuhkan telah dipenuhi.

Metode sampling SDKI 2002-2003 menggunakan rancangan sampling yang kompleks dengan penarikan sampel dilakukan melalui dua atau lebih metode secara bersamaan. Karena alasan tersebut, proses analisis data dianjurkan untuk mempertimbangkan efek desain (design effect) dan pembobotan (weighing). Efek desain adalah membandingkan varians yang diperoleh pada desain sampel yang kompleks, dengan varians yang diperoleh jika survey dilaksanakan dengan desain sampel acak sederhana (Simple Random Sampling). Sedangkan pembobotan (weighing) dilakukan agar varians dalam sampel sama dengan varians dalam populasi untuk mendukung generalisasi ke populasi, selain itu pembobotan dilakukan untuk menyamakan peluang terpilih sebagai sampel dalam setiap strata yang ada.

Data dianalisis dengan menggunakan perangkat lunak SPSS versi 13 lisensi dari IMMPACT-PUSKA FKM UI dan Stat Calc Epi Info 6. Analisis dilakukan dalam beberapa tahapan, yaitu analisis univariat, bivariat, dan multivariat. Tahapan analisis tersebut dilakukan dalam upaya untuk menjawab pertanyaan dan tujuan penelitian.

Dampak faktor risiko terhadap ke jadian kematian perinatal diukur dengan Population Atributable Risk \% yang merupakan persentasi insiden suatu masalah kesehatan pada populasi yang disebabkan oleh suatu pajanan tertentu. Presentasi insiden penyakit di dalam total populasi yang diakibatkan oleh suatu pajanan tertentu. PAR\% dihitung dengan menggunakan rumus PAR $\%=$ PAR $/ \mathrm{I}$.

\section{Hasil}

\section{Analisis Deskriptif}

Dari analisis deskriptif ditemukan angka kematian perinatal pada periode 1997-2003 adalah 2,3\%. Juga ditemukan Proporsi primipara $(77,4)$; kelahiran $<24$ bl dan $\geq 36$ (masing-masing 7,9\%); komplikasi kehamilan dan persalinan $(7,3 \%$ dan $38,4 \%)$; ibu berpendidikan rendah $(44,1)$; kehamilan yang tak diinginkan $(0,5 \%)$ BBLR $(6 \%)$ persalinan non nakes $26,4 \%$; persalinan di 
Tabel 1. Distribusi Responden berdasar Variabel Dependen \& Independent

\begin{tabular}{llcc}
\hline Variabel & Katagori & n & $\%$ \\
\hline Kematian perinatal & Mati & 157 & 2,3 \\
Umur & $<20$ th & 1473 & 21,8 \\
& $\geq 35$ th & 141 & 2,1 \\
Paritas & Primipara & 5230 & 77,4 \\
Jarak Kelahiran & $<24$ bulan & 532 & 7,9 \\
& $\geq 36$ bulan & 536 & 7,9 \\
Komplikasi Kehamilan & Ada & 490 & 7,3 \\
Komplikasi Persalinan & Ada & 2493 & 38,4 \\
Pendidikan Ibu & Rendah & 2980 & 44,1 \\
Status Kehamilan & Tak diinginkan & 36 & 0,5 \\
Berat Bayi Lahir & BBLR & 407 & 6,0 \\
Jenis Kelamin & Wanita & 3328 & 49,2 \\
Penolong Persalinan & Non Kesehatan & 1782 & 26,4 \\
Tempat Persalinan & Non yankes & 3636 & 53,8 \\
Kunjungan ANC & Buruk & 1482 & 21,9 \\
Wilayah Mukim & Rural, GRDP rendah & 2733 & 46,9 \\
Ekonomi Keluarga & Rendah & 3589 & 53,1 \\
& & & \\
\hline
\end{tabular}

Tabel 2. Model Akhir Multivariat untuk Kelompok Primipara ( $\mathrm{n}=5230)$

\begin{tabular}{lccc}
\hline Variabel & Nilai P & OR & 95\% C.I. \\
\hline Ada komplikasi persalinan & 0.816 & 1.07 & $0.60-1.91$ \\
BBLR & 0.000 & 6.56 & $3.50-12.27$ \\
Penolong persalinan non nakes & 0.033 & 4.00 & $1.12-14.34$ \\
Tempat persalinan non faskes & 0.001 & 0.14 & $0.04-0.42$ \\
Kunjungan ANC & 0.103 & & \\
$\quad$ Kurang Baik & 0.061 & 3.93 & $0.94-16.48$ \\
$\quad$ Buruk & 0.033 & 5.19 & $1.14-23.62$ \\
Constant & 0.000 & 0.00 & \\
& & & \\
\hline
\end{tabular}

non yankes 53,8\%; Kunjungan ANC jelek (21,9\%); Bermukim di rural dengan GRD rendah 46,9\%. (Lihat Tabel 1)

\section{Analisis Multivariat}

Ibu primipara dan multipara mempunyai karekteristik yang sangat berbeda dan dengan risiko kematian bayi yang sama-sama tinggi. Selain itu, sebanyak 5230 (77\%) responden merupakan ibu primipara. Pada penelitian ini dikembangkan dua model yang meliputi model primipara (tabel 1) dan non primipara (Tabel 2).

Pada kelompok primipara, pada periode 1997-2003, terlihat bahwa variabel yang berhubungan dengan kematian perinatal di Indonesia, adalah: (1) Jarak kelahiran $<24$ bulan $(\mathrm{OR}=4.03 \mathrm{CI95 \%}$ : 6.14-14.42) dan jarak kelahiran 20-36 bulan (OR=6.14, CI95\%: 1.65 9.84). (2) Komplikasi persalinan ( $\mathrm{OR}=4.00$, CI95\%: 1.12-14.34) (3) BBLR (OR=6.56, CI95\%: 3.50-12.27) (4) Tenaga penolong persalinan non kesehatan $(\mathrm{OR}=4$, CI95\%:1.12-14.34) (5) Tempat persalinan non fasilitas kesehatan $(\mathrm{OR}=0.14$, CI95\%: 0.04-0.42) (5) Riwayat kunjungan ANC yang kurang baik $(\mathrm{OR}=3.93$, CI95\%: 0.94-16.48) (6) Riwayat kunjungan ANC yang buruk $(\mathrm{OR}=5.19$, CI95\%: 1.14-23.62). (Lihat Tabel 2)

Berdasarkan model non primipara, faktor -faktor
Tabel 3. Model Akhir Multivariat untuk Kelompok Non Primipara (n=1528)

\begin{tabular}{llll}
\hline Variabel & Nilai P & OR & 95\% C.I. \\
\hline Jarak Kelahiran & 0.000 & & \\
$\quad<24$ bulan & 0.000 & 6.14 & $2.62-14.42$ \\
24-36 bulan & 0.002 & 4.03 & $1.65-9.84$ \\
Ada komplikasi persalinan & 0.095 & 0.61 & $0.34-1.09$ \\
Tingkat Pendidikan Rendah & 0.017 & 2.00 & $1.13-3.54$ \\
BBLR & 0.107 & 1.92 & $0.87-4.23$ \\
Penolong persalinan non nakes & 0.242 & 0.55 & $0.20-1.50$ \\
Tempat persalinan non faskes & 0.020 & 0.47 & $0.25-0.89$ \\
Kunjungan ANC & 0.968 & & \\
$\quad$ Kurang Baik & 0.999 & 1.00 & $0.44-2.29$ \\
$\quad$ Buruk & 0.869 & 0.93 & $0.37-2.33$ \\
Wilayah tempat tinggal & 0.061 & & \\
$\quad$ Rural, GRDP Tinggi & 0.951 & 0.96 & $0.28-3.30$ \\
$\quad$ Urban, GRDP Rendah & 0.336 & 1.43 & $0.69-2.98$ \\
$\quad$ Rural, GRDP Rendah & 0.017 & 2.40 & $1.17-4.92$ \\
Constant & 0.000 & 0.01 & \\
\hline
\end{tabular}

Tabel 4. Prevalensi Beberapa Faktor Risiko Kematian perinatal di dalam Populasi

\begin{tabular}{llcl}
\hline Variabel & Katagori & Prevalensi (\%) & Sumber data \\
\hline Jarak Kelahiran & $<36$ bulan & 36,0 & BPS, 1997 \\
& $\geq 36$ bulan & 63,0 & dlm USAID, 2002 \\
Kunjungan ANC & Buruk & 17,3 & BPS, 2002 \\
& Baik & 74,6 & BPS, 2002 \\
Berat Bayi Lahir & BBLR & 7,7 & BPS, 2007 \\
& BBLN & 92,3 & BPS, 2002 \\
Penolong Persalinan & Non Nakes & 44,0 & BPS, 2002 \\
& Nakes & 55,0 & BPS, 2002 \\
Tempat persalinan & Non Yankes & 59,0 & BPS, 2002 \\
& Yankes & 40,0 & BPS, 2002 \\
& & &
\end{tabular}

yang berpengaruh meliputi: Jarak kelahiran $<24$ bulan (OR=4.03 CI95\%: 6.14-14.42) dan jarak kelahiran 2036 bulan (OR=6.14, CI95\%: 1.65-9.84). (2) Komplikasi persalinan pada non primipara $(\mathrm{OR}=0.55$, CI95\%: 0.20 1.50); (3) Tingkat pendidikan ibu non primipara yang rendah $(\mathrm{OR}=2$, CI95\%: 1.13-3.54). (3) BBLR pada non primipara $(\mathrm{OR}=1.92$, CI95\%:0.87-4.23). (4) Tenaga penolong persalinan non kesehatan pada non primipara (OR=0.55, CI95\%: 0.20-1.50). (5) Tempat persalinan non fasilitas kesehatan pada non primipara $(\mathrm{OR}=0.47$, CI95\%: 0.25-0.89). (5) Riwayat kunjungan ANC yang kurang baik pada non primipara $(\mathrm{OR}=1.00$, CI95\%: 0.44-2.29). (6) Riwayat kunjungan ANC yang buruk pada non primipara (OR=0.93, CI95: 0.37-2.33); (7) Wilayah tempat tinggal pada non primipara di daerah urban/rural, dengan tingkat GRDP rendah secara berturutturut $(\mathrm{OR}=1.43$, CI95\%: 0.69-2.98) dan $(\mathrm{OR}=2.40$, CI95\%: 1.17-4.92. (Lihat Tabel 3)

\section{Analisis Dampak}

Untuk perhitungan PAR \% dibutuhkan informasi tentang prevalensi Beberapa Faktor Risiko Kematian perinatal di Dalam Populasi. (Lihat Tabel 4)

Berdasarkan perhitungan dengan menggunakan data tentang prevalensi variabel independen yang diamati 
Tabel 5. Hasil Perhitungan Par \& PAR \%

\begin{tabular}{llllll}
\hline Variabel & Katagori & AR & AR $\%$ & PAR & PAR $\%$ \\
\hline Jarak Kelahiran & $<36$ bulan & $-12,30$ & $-9,17$ & $-4,14$ & $-5,20$ \\
Kunjungan ANC & Buruk & $-11,32$ & $-1,16$ & $-97,09$ & $-10,93$ \\
Berat Bayi Lahir & BBLR & 47,10 & 68,63 & 3,77 & 14,90 \\
Penolong Persalinan & Non Nakes & $-7,69$ & $-36,34$ & $-3,67$ & $-14,58$ \\
Tempat persalinan & Non Yankes & $-14,74$ & $-80,22$ & $-9,03$ & $-37,48$ \\
\hline
\end{tabular}

didapatkan nilai PAR \% terendah adalah jarak kelahiran $(-5,2)$ dan tertinggi adalah tempat persalinan $(-37,48)$. Sedangkan nilai PAR \% BBLR dan persalinan non nakes masing masing adalah 14,90 dan -14,58. (Lihat Tabel 5)

\section{Pembahasan \\ Faktor Ibu}

Penelitian ini menemukan bahwa semakin lebar jarak antar kelahiran, maka semakin kecil resiko kematian perinatal. Hal tersebut memperlihatkan pola hubungan dose response yang merupakan salah satu kriteria hubungan kausal yang kuat. Berdasarkan model akhir untuk kelompok non primipara terlihat bahwa variabel jarak kelahiran $<24$ bulan dan 24-36 bulan berhubungan positif dengan kematian perinatal $(\mathrm{OR}=6.14)$ dan $(\mathrm{OR}=4.03)$. Temuan ini konsisten dengan penelitian sebelumnya bahwa bahwa anak-anak yang lahir terlalu cepat setelah kelahiran sebelumnya mempunya resiko kematian lebih besar, terutama apabila selang kelahiran terdekat kurang dari 36 bulan. ${ }^{6}$ Jarak kelahiran yang terlalu cepat dapat mengakibatkan meningkatnya angka kematian perinatal, karena terjadinya "maternal depletion syndrome" . Kondisi kesehatan ibu belum sepenuhnya pulih akibat persalinan sebelumnya dapat mengakibatkan outcome kelahiran yang kurang baik berupa BBLR dan kelahiran prematur. Selain itu, hal tersebut juga disebabkan oleh jabang bayi kekurangan asupan gizi dari ibu yang dapat mengakibatkan IUGR serta tekanan sosial ekonomi yang semakin meningkat akibat biaya yang dikeluarkan pada kehamilan dan persalinan ini. ${ }^{7}$

Salah satu metode yang paling ekonomis dan aman untuk menjaga jarak kelahiran adalah dengan cara memberikan ASI kepada bayi selama mungkin. Lama pemberian ASI dapat berpengaruh terhadap periode tidak haid (amenorrheic) ibu baru melahirkan yang panjang. Semakin lama ibu memberikan ASI kepada bayinya baik secara ekslusif ataupun tidak, semakin lama pula periode tidak haid yang akan dialami maka akan semakin lama kehamilan selanjutnya akan terjadi sebagai akibat ovulasi yang tidak terjadi. ${ }^{8}$
Hubungan antara jarak kelahian dan kematian perinatal menunjukkan pola hubungan dose response, tetapi jarak kelahiran yang terlalu panjang (lebih dari 5 tahun) justru akan meningkatkan resiko untuk mengalami kematian bayi. Hal tersebut terjadi karena setelah lama kehilangan keuntungan biologis dari kehamilan sebelumnya, ibu non primipara akan beresiko kematian perinatal sama dengan ibu primipara. ${ }^{8}$ Sayangnya, penelitian ini tidak dapat membuktikan teori tersebut karena tidak ada data ibu dengan jarak jarak kelahiran $>5$ tahun.

Pada tahapan pengembangan model multivariat, komplikasi persalinan tetap dipertahankan di dalam model. Hal tersebut dilakukan dengan alasan bahwa komplikasi dalam persalinan tersebut sebelumnya tidak dapat dideteksi, meskipun ibu hamil sudah melakukan ANC secara baik. Hal tersebut terjadi karena keterbatasan ANC dalam melakukan deteksi awal potensi timbulnya komplikasi persalinan. ${ }^{9}$ Kondisi yang tidak dapat diduga ini menjadi alasan penulis untuk tetap mempertahankan variabel ini, karena komplikasi persalinan yang terjadi merupakan titik penting keselamatan jiwa ibu dan bayi jika tidak ditangani oleh penolong kesehatan dengan memadai.

Peneliti menyarankan agar data tentang kondisi medis ibu, khususnya tentang riwayat komplikasi persalinan didapatkan dengan melihat catatan kesehatan ibu di fasilitas kesehatan tempat ibu bersalin. Meskipun data yang didapat akan lebih valid, metode ini memiliki kelemahan yaitu hanya dapat menangkap ibu yang melahirkan di fasilitas kesehatan saja. Padahal, berdasarkan data SDKI 2002-2003 ibu yang bersalin di fasilitas kesehatan dilaporkan hanya $40 \% .10$

Pada model non primipara, tingkat pendidikan ibu yang rendah meningkatkan resiko kematian perinatal sebesar 2 kali lebih besar. Temuan ini sejalan dengan temuan banyak studi lain yang menunjukkan hubungan antara pendidikan ibu yang rendah dengan peningkatan resiko kelahiran prematur, kelahiran mati, kematian neonatal dan postneonatal. ${ }^{11}$ Tingkat pendidikan merupakan faktor yang tidaksecara langsung meningkatkan re- 
siko kematian perinatal. Pengaruh tersebut terjadi melalui rendahnya akses ibu berpendidikan rendah terhadap informasi tentang kesehatan ibu dan bayi. Semakin tinggi akses ibu hamil berpendidikan rendah terhadap informasi yang mendukung kesehatan diri dan calon bayinya, terjadi peningkatan pengetahuan ibu yang pada gilirannya akan merubah sikap dan perilaku yang merugikan.

Berdasarkan laporan SDKI 2002-2003, proporsi ibu yang memeriksakan kehamilan hingga lebih dari 4 kali selama kehamilan mencapai $81 \%$ dan hanya $4 \%$ yang tidak pernah memeriksakan kehamilan. Kondisi yang menguntungkan ini seharusnya dapat digunakan sebagai wadah utama untuk meningkatkan keterpajanan ibu hamil khususnya yang berpendidikan rendah terhadap fasilitas pelayanan kesehatan. Kunjungan tersebut dapat dijadikan media melakukan KIE tentang asupan gizi yang cukup, persiapan persalinan, pentingnya bersalin dengan bantuan tenaga kesehatan, serta informasiinformasi yang dapat menambah wawasan ibu mengenai kesehatan ibu dan anak.

\section{Faktor Bayi}

Pada model multivariat akhir untuk kelompok non primipara, BBLR ditemukan merupakan faktor resiko kematian perinatal dengan nilai OR 1.92. Namun hubungan tersebut secara statistik tidak bermakna. Hal tersebut mungkin disebabkan oleh jumlah sampel BBLR yang terlalu kecil. Pada model akhir kelompok primipara ditemukan hasil bahwa bayi berat lahir rendah juga menjadi faktor resiko terhadap kematian perinatal dengan peningkatan resiko menjadi 7 kali lebih besar.

Frekuensi pemeriksaan kehamilan yang dilakukan oleh ibu selama kehamilannya yang rendah sering ditengarai sebagai faktor resiko kejadian BBLR dan outcome kelahiran kurang baik lainnya. Meskipun demikian, kondisi ini masih perlu dicermati, karena penurunan resiko BBLR tidak disebabkan frekuensi pemeriksaan kehamilan, tetapi justru disebabkan oleh identifikasi resiko BBLR secara dini pada saat pemeriksaan kehamilan. Dengan demikian, petugas kesehatan dapat melakukan intervensi yang memadai untuk meningkatkan berat badan bayi melalui berat badan ibu. Itu berarti bahwa semakin muda kehamilan pada saat ibu pertama kali memeriksakan kehamilan, semakin dini pula upaya pencegahan BBLR dapat dilakukan. Peningkatan berat bayi selama kehamilan dapat dilakukan sampai trimester ketiga. Perbaikan status gizi maternal antara lain dapat dilakukan dengan intervensi gizi berupa pembagian suplementasi dan vitamin. Hal tersebut terutama dilakukan pada para ibu yang menderita anemia, kekurangan energi kronis (KEK), dan pertambahan berat badan selama hamil yang kurang.

Strategi pencegahan dan peningkatan perawatan bagi bayi BBLR khususnya di negara-negara berkembang diperlukan dengan segera, karena BBLR merupakan salah satu penyebab utama terjadinya kematian perinatal dan neonatal. ${ }^{1}$ Strategi tersebut adalah mengurangi kelahiran prematur dan bayi IUGR dengan cara meningkatkan status gizi maternal dan deteksi dini serta perawatan infeksi maternal melalui asuhan antenatal yang berkualitas. ${ }^{12}$ Pada penelitian lain, penurunan frekuensi BBLR dapat dilakukan melalui penyuluhan gizi kepada ibu hamil yang dilaksanakan di layanan antenatal di puskesmas, pustu, atau posyandu. Melalui kegiatan tersebut juga dapat dilakukan pemantauan berbagai faktor yang berpengaruh terhadap BBLR, antara lain kenaikan berat ibu hamil, kondisi $\mathrm{Hb}$, dan penapisan ibu hamil resiko tinggi. Selain itu, perawatan pasca persalinan perlu ditingkatkan dengan cara promosi pemberian ASI eksklusif serta penerapan metode transfer kehangatan dari kulit ibu ke kulit bayi. Hal tersebut antara lain dapat dilakukan dengan metode kangguru. Bayi yang sudah dipakaikan popok diletakkan pada badan ibu (di antara kedua payudara ibu) dan kemudian dibebat dengan kain agar tidak terjatuh. Bayi kemudian ditutupi dengan baju ibu untuk menjaga kehangatan tubuhnya dengan menggunakan suhu tubuh ibu.

\section{Faktor Pelayanan Kesehatan}

Dari hasil analisis regresi logistik ganda diketahui bahwa pada model non primipara, tenaga penolong persalinan non kesehatan menjadi faktor protektif terhadap kematian perinatal $(\mathrm{OR}=0.55)$. Sebaliknya, pada model primipara ditemukan hasil yang berbeda, tenaga penolong persalinan non kesehatan justru menjadi faktor resiko terhadap kematian perinatal $(\mathrm{OR}=$ 4). Berdasarkan tempat persalinan, pada kedua model ditemukan hasil yang sama yakni persalinan di fasilitas non kesehatan menjadi faktor protektif terhadap kematian perinatal. Sedangkan untuk variabel kunjungan ANC didapatkan hasil pada model non primipara, kunjungan ANC buruk $(\mathrm{OR}=0.95)$ menjadi faktor protektif terhadap kematian perinatal. Sebaliknya pada model primipara, ibu yang memiliki riwayat kunjungan ANC yang kurang baik/buruk meningkatkan resiko bayinya untuk mengalami kematian perinatal 4-5 kali lebih besar daripada ibu yang memiliki riwayat kunjungan ANC yang baik. Pada model primipara, persalinan dengan tenaga non kesehatan meningkatkan resiko untuk mengalami kematian. Kondisi ini konsisten dengan teori dan hasil penelitian sebelumnya. ${ }^{3-15}$ Sedangkan untuk kunjungan ANC, model primipara memperlihatkan pola hubungan dose response, semakin buruk kunjungan ANC semakin tinggi resiko kematian perinatal. Temuan ini sejalan dengan hasil penelitian sebelumnya. 9,12 


\section{Faktor Lingkungan}

Dari dua variabel faktor lingkungan, hanya satu yang berhasil bertahan pada model multivariat yaitu variabel wilayah tempat tinggal. Variabel ini bertahan pada model non primipara yang memperlihatkan bahwa ibu yang tinggal di wilayah urban ataupun rural dan memiliki GRDP rendah, berisiko 1.5-2.5 kali lebih besar untuk mengalami kematian bayi perinatal daripada yang tinggal di wilayah urban dengan GRDP tinggi. Hasil tersebut tidak ditemukan pada ibu non primipara yang tinggal di rural dengan GRDP tingg yang justru berisiko kematian perinatal lebih tinggi daripada ibu yang tinggal di daerah urban dengan GRDP tinggi.

\section{Dampak}

Penelitian ini juga dapat digunakan untuk menilai program prioritas yang paling efisien dan efektif yang dapat digunakan dalam menurunkan kejadian kematian perinatal di Indonesia. Dengan demikian, pemerintah dapat mengalokasikan sumber daya secara tepat. Penelitian ini menemukan 5 variabel yang dapat dimodifikasi yang dapat dijadikan dasar bagi perbaikan program intervensi meliputi Jarak kelahiran, kunjungan ANC, Berat Badan Bayi penolong persalinan dan tempat persalinan. Kontribusi terbesar diberikan oleh tempat persalinan (PAR \% =37,48).dan terkecil diberikan olen jarak kelahiran (PAR $\%=-5,2)$.

\section{Kesimpulan}

1. Jarak kelahiran $<24$ bulan dan $24-36$ bulan, pada ibu non primipara, berisiko kematian perinatal lebih tinggi daripada jarak kelahiran $>36$ bulan.

2. Komplikasi persalinan pada ibu primipara, berisiko kematian perinatal hampir sama dengan ibu yang tanpa komplikasi persalinan, tetapi pada ibu non primipara, justru berisiko kematian perinatal lebih rendah daripada.

3. Tingkat pendidikan yang rendah, pada ibu non primipara beresiko kematian bayi perinatal lebih tinggi daripada ibu dengan tingkat pendidikan yang tinggi.

4. Bayi BBLR, pada ibu primipara dan non primipara, beresiko kematian bayi perinatal lebih besar daripada bayi BBLN.

5. Persalinan non tenaga kesehatan, pada ibu primipara berisiko kematian bayi perinatal lebih tinggi, tetapi pada ibu non primipara, beresiko kematian perinatal lebih rendah daripada persalinan tenaga kesehatan.

6. Persalinan di non fasilitas kesehatan, pada ibu primipara dan non primipara, berisiko kematian perinatal lebih rendah daripada persalinan di fasilitas kesehatan.

7. Kunjungan ANC yang buruk, pada ibu primipara beresiko kematian perinatal lebih tinggi, tetapi pada ibu non primipara, berisiko kematian bayi perinatal lebih rendah daripada yang dengan riwayat ANC baik.

8. Variabel yang dapat dimodifikasi dapat dijadikan dasar perbaikan program intervensi, adalah Jarak kelahiran, kunjungan ANC, Berat Badan Bayi penolong persalinan dan tempat persalinan. Kontribusi terbesar diberikan oleh tempat persalinan (PAR \% $=37,48)$. dan terkecil diberikan olen jarak kelahiran (PAR \% =-5,2). Penolong persalinan \& BBLR kerkontribusi sedang (14, 58 dan 14,90\%).

\section{Saran}

1. Upaya KIE pada ibu hamil hendaknya diarahkan pada upaya memperbesar jarak kelahiran menjadi lebih besar dari 36 bulan dengan cara memperpanjang periode pemberian ASI dan menggunakan alat kontrasepsi.

2. Pemeriksaan kehamil ibu primipara yang pendidikan rendah perlu lebih ditingkatkan untuk menyampaikan informasi tentang asupan gizi, persiapan persalinan, persalinan tenaga kesehatan dan lain-lain.

3. Melaksanakan program pemberikan makanan suplementasi kepada ibu hamil yang berisiko tinggi melahirkan BBLR.

4. Memberikan perawatan skin to skin (metode kangguru) kepada bayi BBLR sehingga dapat menjaga kehangatan bayinya agar organ-organ tubuh bayi menjadi cepat matang.

5. Menganjurkan persalinan pada tenaga kesehatan yang terampil merawat bayi BBLR sehingga terhindar dari kematian perinatal.

6. Melakukan studi lanjutan dengan disain studi kohort terhadap variabel-variabel yang berpengaruh secara controversial terhadap kematian perinatal. Studi ini dapat dilakukan di daerah penelitian yang sudah memiliki sistem pencatatan kohort ibu dan kohort anak yang baik dan lengkap seperti Kabupaten Subang, Jawa Barat.

\section{Daftar Pustaka}

1. Promoting Quality Maternal and Newborn Care: A Reference Manual for Program Managers, CARE :USAID, 1998

2. Kramer, Michael S, et al., Analysis of Perinatal Mortality and Its Components: Time for a change?, American Journal of Epidemiology, Volume 156, Number 6 (493-497), 2002

3. Child Health Research Project Special Report: Reducing Perinatal and Neonatal Mortality, USAID, 1999

4. Neonatal and Perinatal Mortality, Country, Regional, and Global Estimates, WHO, 2006a

5. Survey Demografi Kesehatan Indonesia 2002-2003, BPS. BKKBN. Depkes RI \& Macro International Inc. (IMI). Jakarta, 2003

6. Actual versus preffered birth intervals, USAID \& John Hopkins University. 2002, Population Information Program, Volume XXX No. 3

7. Gap between Preffered and Actual Birth Intervals in Sub-Saharan Africa : Implications for Fertility and Child Health, DHS Analytical Studies, Rafalimanana, 2001

8. Birth Spacing: Three to Five Saves Lives. Population Reports, Series L, No. 13. Baltimore, Johns Hopkins Bloomberg School of Public Health, 
Population Information Program., Setty-Venugopal, V. dan Upadhyay, U.D. 2002

9. Labour complications remain the most risk factors for perinatal mortality in rural Kenya, Bulletin of the World Health Organization, 2003, Ronsmans, Carine et al. 2003

10. Survey Demografi Kesehatan Indonesia 2002-2003. BPS. BKKBN. Depkes RI \& Macro International Inc. (IMI). Jakarta, Luo, ZhongCheng, et al. 2006

11. Luo, Zhong-Cheng, et al. 2006, Effect on neighbourhood income and maternal education on birth outcomes: a population-based study, Canada's Leading Medical Journal, 9 May 2006

12. Ronoatmodjo, Sudarto. 1996, Faktor Resiko Kematian Neonatal di
Kecamatan Kruak Nusa Tenggara Barat 1992-1993. Disertasi Bidang Ilmu Kesehatan Masyarakat Program Pascasarjana Universitas Indonesia, Depok

13. Alisjahbana, A. 1985, Kematian Perinatal dan Faktor-faktor yang Berhubungan dengan Masalah ini dalam Sri Kardjadi dkk., Aspek Kesehatan dan Gizi Anak Balita. Yayasan Obor Indonesia

14. WHO. 2006a, Neonatal and Perinatal Mortality, Country, Regional, and Global Estimates

15. WHO. 2006b, Making a Difference in Countries, Strategic Approach to Improving Maternal and Newborn Survival and Health. Department of Making Pregnancy Safer 